\title{
viewpoint
}

\section{Science and culture}

\author{
Western science could learn a thing or two from the way science is done in other cultures
}

\author{
Maurizio Iaccarino
}

W hat we understand today as being 'modern science' is in fact not that modern, but was born nearly half a millennium ago at the time of the Renaissance in Europe. But even if we think of great Renaissance thinkers, such as Galileo Galilei, Leonardo da Vinci or Sir Isaac Newton, as the first 'true scientists', we should not forget that all civilizations throughout history have produced and accumulated knowledge to understand and explain the world, a process that was often accompanied or stimulated by technological development. Indeed, the explosion of knowledge during the Renaissance was sparked by a reawakened interest in the writings of Greek, Roman and Arab philosophers and scholars-the word 'Renaissance' implying a renewed interest in classical culture and knowledge. But regardless of the various cultures and civilizations that have influenced science, what is common to all scientists is that they study natural phenomena, with an appropriate set of rules, to make generalizations and predictions about nature.

\section{science is part of culture, and ... how science is done largely depends on the culture in which it is practised}

However, most modern studies of the world around us are empirical, and there is clearly much more to understand than what is being studied by scientists. The understanding of complex systems remains a major challenge for the future, and no scientist today can claim that we have at hand the appropriate methods with which to achieve this. Thus, we cannot discuss the future of science without taking into account the philosophical problems generated by the study of complexity. Modern, or Western, science may not be best suited to fulfil this task, as its view of the world is too constrained by its characteristic empirical and analytical approach that, in the past, made it so successful. We should therefore remember the contributions of other civilizations to the understanding of nature-in particular the perception of the world in areas such as Asia and Africa, or among the indigenous people of Australia and South America. Such traditional or indigenous knowledge is now increasingly being used not only with the aim of finding new drugs, but also to derive new concepts that may help us to reconcile empiricism and science.

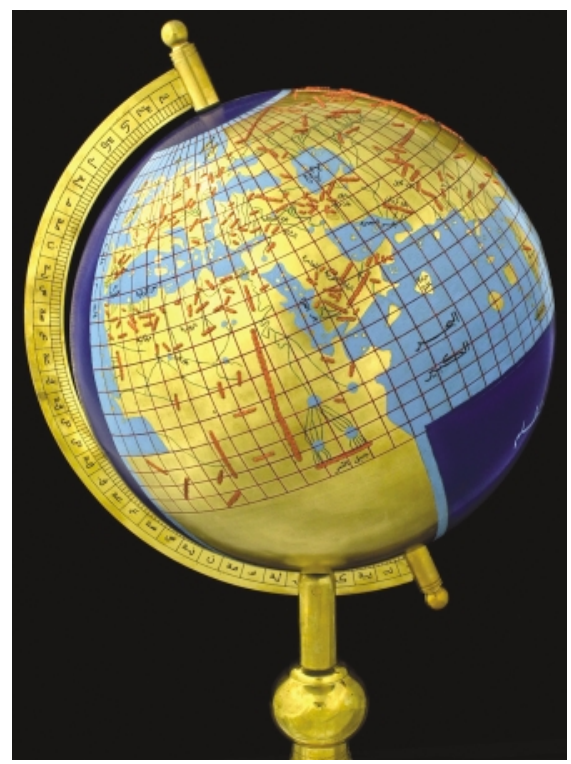

This globe, based on a world map from the early ninth century, was commissioned by Calif alMa’mûn in Baghdad. Image courtesy of Fuat Sezgin, Institute for the History of Arab-Islamic Sciences, University of Frankfurt, Germany.
During the Renaissance, European scientists and philosophers started challenging long-held beliefs and developed a new natural philosophy. Science and the arts truly flourished in Europe, and this was caused and furthered by various positive developments that took place at that time. Most importantly, the new philosophy started a process that eventually led to the independence of scientific thought and theories from myths, religion and theology. Second, the interaction among different European cultures stimulated creativity through new ways of thinking and new paradigms for the observation of nature. Last, but not least, the foundation of scientific academies, notably the Accademia dei Lincei, the Royal Society and the Académie des Sciences, and the establishment of universities throughout Western Europe, contributed to scientific progress through the dissemination of new knowledge.

$\mathrm{B}$ ut the foundations of modern science were laid long before this time, and were particularly influenced by Islamic civilization. The Muslims were the leading scholars between the seventh and fifteenth centuries, and were the heirs of the scientific traditions of Greece, India and Persia. After appropriation and assimilation, they built on these discoveries, and developed a truly Islamic science that led worldwide knowledge in all scientific fields, including medicine. These activities were cosmopolitan, in that the participants were Arabs, Persians, Central Asians, Christians and Jews, and later included Indians and Turks. The transfer of the knowledge of Islamic science to the West through various channels paved the way for the Renaissance, and for the scientific revolution in Europe. The public in the West is 


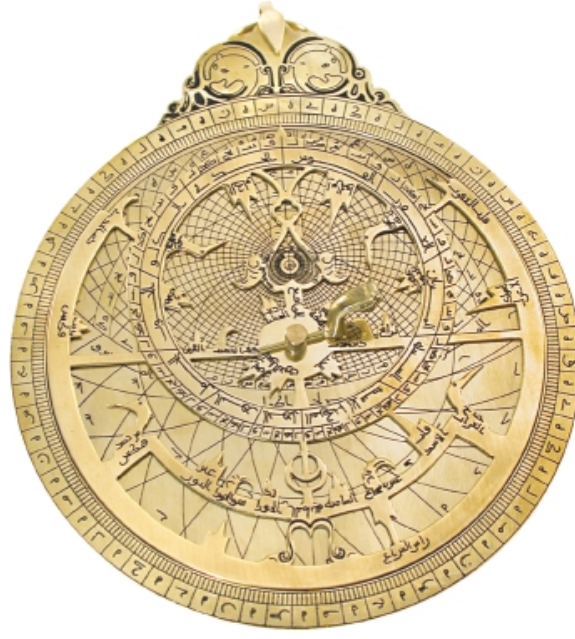

Replica of an astrolab built in $984 \mathrm{AD}$ by the great Persian astronomer and mathematician al-Khujandî. The original is displayed in the National Museum of Qatar. Image courtesy of Fuat Sezgin, Institute for the History of Arab-Islamic Sciences, University of Frankfurt, Germany.

generally unaware of this important contribution to modern science and to the culture of the Middle Ages. Islamic civilization is part of our own heritage, and the great Islamic scientists whose works were translated into Latin, such as Jabir ibn Hayan (Geber), Ibn Sina (Avicenna), al-Razi (Rhazes), Ibn al-Haytham (Adhazin) and alKhuwarizmi, are as important as any great European scientist. The pictures in this article illustrate some of the remarkable products of Islamic science.

The Renaissance scientists who built on this knowledge-as well as all their predecessors and colleagues in other civilizations-wanted to understand and describe the causes and effects of the events they observed in nature. Indeed, Aristotle and Plato were probably the first to state that our understanding of the natural world is based on a set of a priori beliefs, namely concerning ideal objects or universal values, that allow us to imagine and describe the world around us. Religious people believe that God dictates these universal values; agnostics and atheists believe that universal values are inherent in the human reason'. These transcendental values are the source of human beliefs that guide humanity towards social and ethical rules and to the observation of nature (laccarino, 2001a; Stent, 1974). In other words, science is deeply rooted in metaphysics, and there is no conflict between religion and science. Moreover, although the language of science is often specialized, and thus inaccessible to non-specialists, science and culture are not different entities: science is part of culture, and how science is done largely depends on the culture in which it is practised.

Science has had an increasingly strong influence on European culture. In the nineteenth century the buzzword for science was 'order'. Scientists had discovered that the movement of the stars is predictable, and that all terrestrial and celestial phenomena follow the same scientific laws like clockwork. They believed, according to the Galileian vision, that the book of nature is written in the language of mathematics, with characters represented by geometric objects. The mission of science was to discover the laws of nature, and thereby explain all natural phenomena. This faith in science gave rise to the philosophical movement called positivism, which led to a widespread trust in science and technology and influenced social theory. Even after positivism faded out, the Darwinian theory of evolution still influenced social phenomena, most notoriously eugenics and racism. The faith in the possibilities offered by scientific progress still shapes the beliefs and actions of people today; in fact, expressions such as "this has been scientifically demonstrated," are often used to cut short a discussion.

7 he work of scientists implies that they challenge accepted explanations of facts and propose new and original ways of interpreting them. Originality, independence of thought and dissent are characteristics of the scientific culture, and therefore a challenge to established cultural values. The safeguards for independence are free inquiry, free thought, free speech, tolerance and the willingness to arbitrate disputes on the basis of evidence. These values are not important for science itself, but have had a strong influence on the development of today's democratic and free societies. The success of science, and the use of scientific knowledge, have profoundly changed everyday life, mainly in developed countries. Life expectancy has increased strikingly and cures are available for many diseases; agricultural productivity has increased to match demographic developments; and technology has freed humankind from arduous labour. New methods of communication, information handling and computation have brought unprecedented opportunities and challenges (laccarino, 2000, 2001b). These discoveries or inventions have radically changed our way of describing the natural world, and have influenced our everyday life. Today, even the organization of society itself owes much to scientific thinking (UNESCO/ISCU, 1999).

Most of this progress took place in Europe, and later in North America, and these continents are still the primary players in science. Table 1 shows that, during the past decade, three-quarters of the world's scientific publications came from Western Europe and North America; and if we take the award of the Nobel Prizes for science as an indicator of scientific excellence, we can see from Table 2 that more than $90 \%$ of the laureates in the natural sciences are also from Western countries, despite the fact that they are home to only $10 \%$ of the world's population. The small number of Nobel laureates from the rest of the world reflects differences in culture and in the type of education offered, as well as a lower level of financial support for science.

The governments of developed countries consider science and technology as essential for economic progress and military power, and therefore allocate abundant financial resources to education and research. In turn, a stimulating cultural environment, partly due to the high level of education, attracts investments in private research, thus adding to the public commitment to science. It is fair to say that in the past few centuries science has had a strong influence on cultural values all over the

Table 1 I Worldwide scientific publications

\begin{tabular}{lcc}
\hline & $\begin{array}{l}\mathbf{1 9 9 7} \\
(\%)\end{array}$ & $\begin{array}{l}\text { Change after } \\
\mathbf{1 9 9 0}(\%)\end{array}$ \\
\hline Western Europe & 37.5 & 110 \\
\hline North America & 36.6 & 92 \\
\hline Industrial Asia & 10.8 & 126 \\
\hline Former Soviet Union & 3.7 & 54 \\
\hline Oceania & 2.8 & 107 \\
\hline China & 2.0 & 170 \\
\hline India & 1.9 & 89 \\
\hline Latin America & 1.8 & 136 \\
\hline Southern and & 1.9 & 120 \\
Eastern Mediterranean & & \\
\hline Sub-Saharan Africa & 0.7 & 72 \\
\hline Rest of Asia & 0.5 & 98 \\
\hline
\end{tabular}

Source: Indicateurs 2000, Observatoire des Sciences et des Techniques, Paris (www.obs-ost.fr/en/) 
Table 2 | Nobel laureates in natural sciences (1901-1998) by geographical region

\begin{tabular}{lcc}
\hline Region & $\begin{array}{l}\text { Number of } \\
\text { laureates }\end{array}$ & Percentage \\
\hline Western Europe & 230 & 50.0 \\
\hline North America & 200 & 43.0 \\
\hline Eastern Europe & 13 & 2.8 \\
\hline Asia & 9 & 1.9 \\
\hline Australasia & 4 & 0.8 \\
\hline Latin America & 3 & 0.6 \\
\hline Africa & 1 & 0.2 \\
\hline Arabic region & 0 & 0.0 \\
\hline
\end{tabular}

world, but not always a positive one. In developing countries, science education is based on Western concepts and culture, and it is taught by those for whom science is often unrelated to their culture. This leads students to deny the validity and authority of the knowledge transmitted to them by their parents and grandparents and creates tension in several societies. Even in developed countries, general education is a recent trend. In 1913, J. McKeen Cattell, the Vice President of the American Association for the Advancement of Science stated that: "There is not a single mulatto who has done creditable scientific work" (Cattell, 1914). His remark reflects the cultural attitude at the turn of the twentieth century in the USA, which deprived black people of an appropriate education, and as a consequence, made them less interested in pursuing a scientific career. Similarly, many countries took equally as long to grant women the same rights as men and thereby enable them to participate in scientific enterprise.

B ut what do we mean by 'modern science'? The main characteristic of this approach is to understand nature by analysing each phenomenon according to a predetermined set of rules. Scientific work may be descriptive, as in the case of cosmology, palaeontology or anatomy. These descriptions then lead to theories or paradigms, according to Kuhn (1970), that interpret the causes and effects of events, and that can be tested through experiments. When these experiments prove that the theory is wrong, new hypotheses are made and tested. To quote Bertold Brecht in his play about Galileo: "The aim of science is not to open the door to infinite wisdom, but to put a limit to infinite error."

Another characteristic of science is that it builds on the past, such that it is incremental.
As each scientific discipline describes a specific field based on a set of established rules-for example, the description of biology at the anatomical, histological, cellular or biochemical level-each type of description becomes more and more complete with time. Does it come to an end, as Gunther Stent declared for molecular biology in 1968 (Stent, 1968)? Stent started his scientific career when many people believed, in the framework of vitalistic theories, that it was not possible to interpret the inheritance of genetic traits in chemical terms. The elucidation of the genetic code was a victory for him, but at the same time the end of a challenge. Stent's statement upset many scientists of the time who believed that molecular biology was still alive, and we have indeed subsequently witnessed an enormous number of new discoveries and new knowledge in this field. However, it is true that after 1968 work on the elucidation of the genetic code consisted only of finding out the details. I believe that specific types of scientific description do

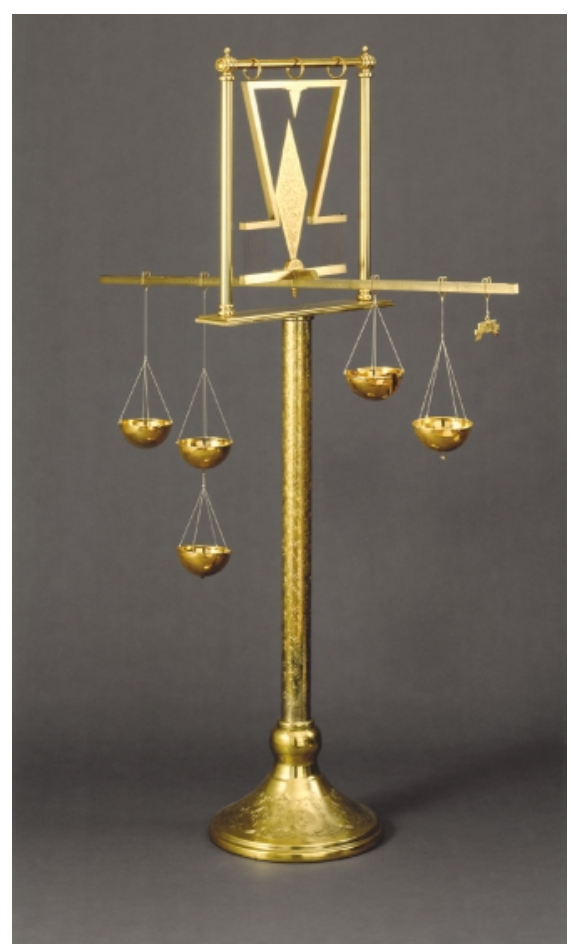

This extremely exact ‘Balance of Wisdom' was built at the Institute for the History of Arab-Islamic Sciences according to the description by Abdarrahmânal-Khâzinî from Khorasan in Northeast Persia, who perfected and described it in the first half of the twelfth century. Image courtesy of Fuat Sezgin, Institute for the History of Arab-Islamic Sciences, University of Frankfurt, Germany. approach an end, as is the case for anatomy, which was actively studied many years ago, whereas today this knowledge is mostly obtained through textbooks.

Scientists have been very successful in studying specific aspects of the natural world that are amenable to observation and experimentation, because the necessary theoretical and technical tools have been available; this is true for microbiology and the discovery of the causative agents of infectious diseases at the end of the nineteenth century, and for the discovery of vitamins in the first decades of the twentieth century. Scientists work on simple systems, which are usually idealized or primitive models of a real situation. They also work at a specific level of analysis; for example, the physics of elementary particles does not contribute to the interpretation of the mechanism of muscle contraction. To use the words of Albert Szent-Gyorgyi: "In my quest for the secret of life I started my research in histology. Unsatisfied by the information that cellular morphology could give me about life, I turned to physiology. Finding physiology too complex, I took up pharmacology. Still finding the situation too complicated, I turned to bacteriology. But bacteria were even too complex, so I descended to the molecular level, studying chemistry and physical chemistry. After twenty years' work, I was led to conclude that to understand life we have to descend to the electronic level and to the world of wave mechanics. But electrons are just electrons and have no life at all. Evidently on the way I lost life; it had run out between my fingers."

Szent-Gyorgyi describes today's problems of science: the inability to integrate results and concepts that come from different approaches and levels of analysis. The reductionistic approach of most scientists is to ignore selected facts and to propose a model that is based on what they consider to be key observations, which is certainly useful when the model can be experimentally tested. Biological phenomena are studied at different levels of organization, and the theories formulated at each level can explain only a specific set of facts. When proceeding from a simple level towards a more complex one, new behaviours emerge. In other words, the whole is more than the sum of the parts, or different from the sum of the parts. For example, the properties of a protein are different from the sum of the properties of each amino acid from which it is composed. The properties 
of biological structures made of macromolecules held together through non-covalent interactions are different from the sum of the properties of each macromolecule. The study of such complex systems in biology or in other disciplines remains a major challenge for the future, and may require a change in approach.

$\mathrm{n}$ this endeavour, we might find it useful to compare Western science with traditional knowledge. Whereas Western science favours reductionist, mechanistic and quantitative methods, traditional knowledge observes natural phenomena from a global point of view. These observations are strictly linked to local culture and to the predominant philosophy. In pre-colonial Africa, specialists knew well the characteristics of the local climate and soil, and were able to give expert advice on where and when to grow crops. They had a precise knowledge of the tropical flora, and of desert bushes, and developed a sophisticated classification system of plants into families and groups, based on their cultural and ritual properties. Mayan scientists in South America developed a highly sophisticated calendar through their observations of the Sun and the stars. American Indians and Australian aborigines have gathered an immense amount of biological knowledge based on their observations of nature. The medical theories of the Yorubas of Nigeria included the concept of invisible entities causing infectious diseases, analogous to the bacteria of Western medicine. Science and technology in Africa were once quite advanced, comparable to European levels of the time, in the fields of human and veterinary medicine, agriculture, food conservation, fermentation, metallurgy and the preparation of soap and cosmetics (Mazrui \& Ade Ajayi, 1998). Cultures from all regions of the world have developed a complex view of nature, rooted in their philosophy, which has led to their understanding and explanation of the natural world. The traditional knowledge of non-European cultures is the expression of specific ways of living in the world, of a specific relationship between society and culture, and of a specific approach to the acquisition and construction of knowledge. This knowledge provides much of the world's population with the principal means by which they fulfil their

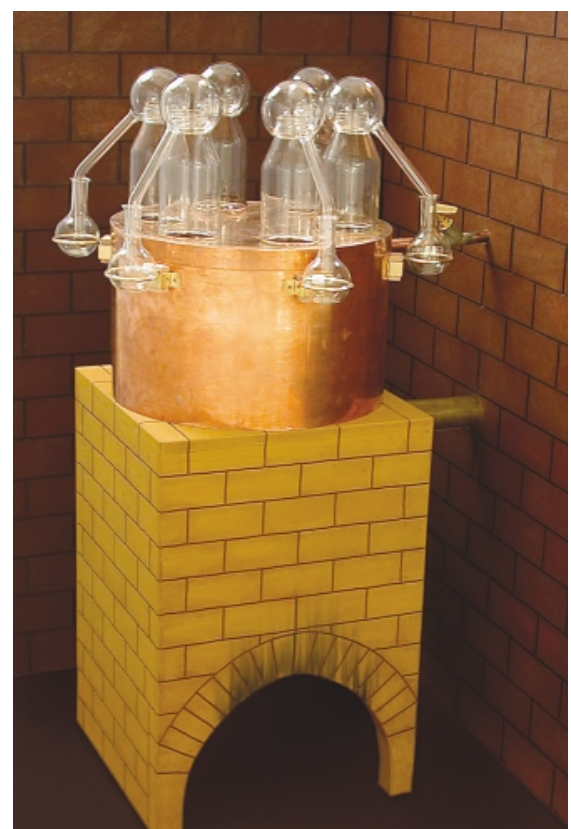

Apparatus for distilling rose water. Replica built by the Institute for the History of Arab-Islamic Sciences, according to a description by the physician az-Zahrâwî from the late tenth century in Muslim Spain. Image courtesy of Fuat Sezgin, Institute for the History of Arab-Islamic Sciences, University of Frankfurt, Germany.

basic needs. But colonization by Europeans destroyed much of this indigenous knowledge and replaced it with the European educational and political system that consequently devalued what was left of it. Slowly, the importance and influence of traditional knowledge diminished because of the success of modern science and technology and the economic power that accompanies it. For these reasons, the knowledge systems of other cultures concerning the observation of nature are all but lost to the Western world.

This is a great loss for modern science. Although it has attained a dominant position, other knowledge systems do exist, and we should accept that our understanding of science is one knowledge system among many others (Nakashima, 2000). Traditional knowledge does not divide observations into different disciplines to the same extent as science, and this more synthetic and holistic approach may help to develop new paradigms for the observation and study of complex phenomena. Most of our observations of the natural world are empirical, and scientists offer a scientific explanation for only a part of them. The traditional knowledge of non-Western cultures puts empirical observations into a different, larger context. Thus, in all cultures, we try to harmonize empirical observations in order to describe nature and to be able to interpret and predict it. As modern science is reaching its limits when attempting to explain the inner workings of the world around us, we should perhaps remember and re-evaluate the contributions of other cultures to the understanding of nature, as the Renaissance scientists did with the ancient knowledge of the Greek and Arab scholars.

\section{REFERENCES}

Cattell, J.M. (1914) Correspondence, Science, 39, 154-164.

laccarino, M. (2000) in Proceedings of the World Conference on Science, 6-9 (ed. Cetto, A.M.). Banson, London, UK.

laccarino, M. (2001a) Science and ethics. EMBO Rep., 2, 747-750.

laccarino, M. (2001b) A vision for European science. EMBO Rep., 2, 259-262.

Kuhn, T.S. (1970) The Structure of Scientific Revolutions. University of Chicago Press, Illinois, USA.

Mazrui, A.A. \& Ade Ajayi J.F. (1998) in Histoire Générale de l'Afrique, VIIIA, 697-745 (eds Mazrui, A. \& Wondji, C.) UNESCO Publishing, Paris, France.

Nakashima, D. (2000) In Proceedings of the World Conference on Science, 442-444 (ed. Cetto, A.M.) Banson, London, UK.

Stent, G.S. (1968) That was molecular biology that was. Science, 160, 390-395.

Stent, G.S. (1974) Molecular biology and metaphysics. Nature, 248, 779-781.

UNESCO/ICSU (1999) Declaration on science and the use of scientific knowledge. http://www.unesco.org/science/wcs/eng/declar ation_e.htm

This text is an elaboration of a speech given at the Plenary Session of the Pontifical Academy of Sciences at the Vatican in November 2002.

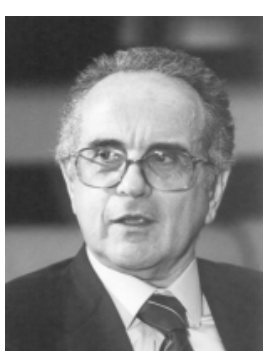

Maurizio Iaccarino is Secretary General of the UNESCO/ICSU World Conference on Science and at the Institute of Genetics and Biophysics, CNR, in Naples, Italy. E-mail: iaccarin@ iigb.na.cnr.it

doi:10.1038/sj.embor.embor78 